\title{
Evaluation of Pharmacy Student's Placements Experience at Community Pharmacy Settings in Riyadh, Saudi Arabia
}

\author{
Mohamed N Al-Arifi \\ Department of Clinical Pharmacy, College of Pharmacy, King Saud University, Riyadh, SAUDI ARABIA.
}

\begin{abstract}
Objective: To assess opinions of pharmacy students towards community pharmacy placements experience. Methods: A cross-sectional study of male pharmacy students were conducted at king Saud university college of pharmacy. Data was collected by self-administered questionnaire for the period of June 2020 to July 2020. Deceptive statistics was applied to describe variable study. Results: A total of 77 out of 120 pharmacy students were returned the survey. Less half of the students $(46.8 \%)$ agreed that their pharmacy preceptors organized interesting learning activities (either agreed or strongly agreed). A minority of students agreed that workload allocation in their workplace training was carefully planned. About $60 \%$ of students reported that their community pharmacy placements were a waste of time. Additionally, $32.5 \%$ of students stated that no one at the community pharmacy placement staff was interested in their problems. Only $37.8 \%$ of the students enjoyed working at their community pharmacy
\end{abstract}

placements, and about $46 \%$ of the students stated that they would like to return to their pharmacy placements. Conclusion: Findings shows that the pharmacy students had relatively low engagement with their pharmacy experiential placements. Pharmacy students had experienced low levels of satisfaction during their community pharmacy experiential placements. Key words: Pharmacy students, Placements, Preceptors, Saudi Arabia, Community pharmacy, Learning, Experience.

\section{Correspondence}

Dr. Mohamed N Al-Arifi

Department of Clinical Pharmacy, College of Pharmacy, King Saud University, Riyadh-11451, SAUDI ARABIA.

Email: malarifi@ksu.edu.sa

DOI: 10.5530/jyp.2021.13.29

\section{INTRODUCTION}

Getting employment is important for students after completion of their academic careers. ${ }^{1}$ Placements have been reported as integral components of the student curriculum, providing opportunities for undergraduates to have authentic experiences and to develop their knowledge and skills by engaging with the environment. ${ }^{1-4}$ Several decades ago, the practice of pharmacy was recognized in Saudi Arabia with the introduction of Bachelor in Pharmacy program at King Saud University, with several changes and expanded courses over the years. ${ }^{5,6}$ Undergraduate and postgraduate pharmacy students have a variety of employment opportunities such as pharmaceutical industries, clinical hospital settings, community and retail settings, and academic or research positions. The most common and easily obtained pharmacy employment opportunity is in the community retail outlets as community pharmacists. ${ }^{6}$

Community pharmacists are frontline professionals in the provision of medication to consumers, and they are recognized as the primary source of information on medicine in many parts of the world. ${ }^{7}$ Community pharmacists play vital roles in the appropriate and effective use of medications. They are involved in dispensing life-saving medication, giving health advice, and treating minor ailments. ${ }^{8}$ Community pharmacists often run commercial businesses alongside their healthcare service, and they may encounter dramatic dilemmas. ${ }^{89}$ Despite of the multiple options for pharmacists to practice their profession, many community and retail pharmacies have insufficient numbers of pharmacists. Pharmacies in community settings in Saudi Arabia are often not well-developed, and a very small number of graduates practice in community pharmacies. ${ }^{10}$ Indeed, most Saudi community pharmacists did not complete their pharmacy education in Saudi Arabia. ${ }^{5}$ Most Saudi students and pharmacists prefer to work in hospital settings rather than community pharmacies, ${ }^{10}$ with only $2 \%$ of students interested in working in community settings in Saudi Arabia. This large difference in available positions in the working sector and the preferences of students is reportedly due to issues related to learning and development, communication skills, and fulfilling career choices. ${ }^{11}$

Everyday activities of the pharmacist were largely dependent on the readiness and capabilities of the pharmacists serving as preceptors for their work teams in community or hospital settings. The increasing number of students entering pharmacy courses is creating additional challenges due to the corresponding increase in the number of pharmacists and placement sites required to provide quality educational experiences. $^{12}$ This report underlines an important opportunity to improve practices in community settings.

In Saudi Arabia, pharmacists are typically under the jurisdiction of the Ministry of Health. The Saudi Pharmaceutical Society can play an important role in collaborating with pharmacy practitioners, pharmacy educators, and health regulators. Previous studies have reported that many community pharmacists in Saudi Arabia lack the necessary training and clinical skills as well as most importantly, there are considerable gaps in the knowledge, skills, training of community pharmacists and a lack of continuous pharmaceutical education. ${ }^{10,11}$ A study has been conducted in Saudi Arabia to assess pharmacy students' attitude and perception about employed in a community pharmacy in future. A recent study was conducted among Saudi pharmacy to assess their general attitude and knowledge about working in community pharmacy. This study did not focus on pharmacy student trainees during their placements. It found that most of pharmacy students don't have good knowledge or training in community pharmacy, so minority of students were interested in working as community pharmacist. ${ }^{13}$ It is important to address

This is an open access article distributed under the terms of the Creative Commons Attribution-NonCommercial-ShareAlike 4.0 License, which allows others to remix, tweak, and build upon the work non-commercially, as long as the author is credited and the new creations are licensed under the identical terms. 
these issues in order to improve community pharmacy experiential placements. However, we must first investigate the opinions of pharmacy student trainees during their placements.

\section{MATERIALS AND METHODS}

\section{Study Design and Setting}

A cross sectional study was conducted among 120 senior pharmacy students at the College of Pharmacy, King Saud University from June 2019 to July 2019. Students had been practicing at community pharmacies during their fourth to sixth years of study. We included senior students from king Saud university college of pharmacy and junior students and students from other colleges were excluded. A paper based validated self-administered questionnaires were used to collect the data among senior pharmacy students who were currently enrolled in internship in various community pharmacies.

\section{Questionnaires Design}

The survey consisted of 21 questions, with four subscales that included the most important aspects of clinical practice (Table 1). The first subscale deals with engagement (11 items), second section about dissatisfaction (4 items), third part ask about satisfaction (3 items), and the last subscale consisted of motivation items (3-questionniares). Data were collected on a 5-point Likert scale (strongly disagree, disagree, neither agree nor disagree, agree, and strongly agree) adapted from previous studies published in this regards. ${ }^{1}$ For the positive inquiries, the scores for the Likert scale were 1 (strongly disagree) to 5 (strongly agree), and for the negative inquiries the scores were reversed. The total score was determined by dividing the sum of the scores by the total number of items. Higher scores indicated positive opinions about the community pharmacy experiential placements.
The original survey was subjected to pilot testing. The Pilot testing was carried out among a group of 10 students was conducted to examine the readability, difficulty, and understanding of the questionnaires prior to administering it. The Cronbach's alpha values for staff engagement 0.87 , for student motivation 0.75 , student satisfaction 0.67 , and for student dissatisfaction 0.78 .

\section{Statistical Analysis}

Statistical Package for Social Sciences version 25 (SPSS) software was applied to analyze the data. Descriptive statistics was used.

\section{RESULTS}

A total of 77 of the 120 students completed the survey, giving a response rate of $64.2 \%$. The details on students' opinions of engagement during their pharmacy placements are shown in Table 2. The mean score for the engagement subscale was 3.2 out of 5 . Fewer than half of the students $(46.8 \%)$ agreed that their pharmacy preceptors organized interesting learning activities (either agreed or strongly agreed). Nearly one-third of the students stated that their preceptors helped them when they had trouble with work. About $30 \%$ of students reported that the assignments during their workplace placements were clear. A minority of the students agreed that workload allocation in their workplace training was carefully planned. Students showed a high level of Displeasure with their community pharmacy placement experiences. The average student opinion score was 3.1, which is almost neutral (Table 2). For example, $39.0 \%$ of students felt that their community pharmacy placement was boring (agreed or strongly agreed). About $60 \%$ of students believed that their community pharmacy placements were a waste of time. Moreover, $32.5 \%$ of students reported that no one at the community pharmacy placement staff was interested in their problems (Figure 1). The mean score for Displeasure was $3.1 \pm 0.8$ (Table 2).

Table 1: Pharmacy Student opinions about their placement experience.

\begin{tabular}{|c|c|c|}
\hline Subscales & No. & Items \\
\hline \multirow[t]{11}{*}{ Commitment } & Item 1 & The pharmacy Preceptor often thinks of interesting learning events. \\
\hline & Item 2 & There are opportunities for me to proceed at my own pace. \\
\hline & Item 3 & The pharmacy Preceptor working with me helps me when I am having trouble with the work. \\
\hline & Item 4 & I have a say in how my placement day is spent. \\
\hline & Item 5 & Placement workplace assignments are clear so that I know what to do. \\
\hline & Item 6 & Pharmacy Preceptor tells me how and why they are doing things \\
\hline & Item 7 & The pharmacy Preceptor is unfriendly and inconsiderate towards students (-ve). \\
\hline & Item 8 & The pharmacy Preceptor working with me considers my feelings. \\
\hline & Item 9 & Workload allocation in this workplace is carefully planned. \\
\hline & Item 10 & The pharmacy Preceptor working with me goes out of his/her way to help me. \\
\hline & Item 11 & The staff are punctual here. \\
\hline \multirow[t]{4}{*}{ Displeasure } & Item 12 & This is a disorganized clinical placement. (-ve) \\
\hline & Item 13 & This clinical placement is a waste of time. $\left(-\mathrm{ve}^{*}\right)$ \\
\hline & Item 14 & This clinical Placement is boring. (-ve) \\
\hline & Item 15 & No one is interested in my problems. (-ve') \\
\hline \multirow[t]{3}{*}{ Fulfillment } & Item 16 & I enjoy coming to this workplace. \\
\hline & Item 17 & This clinical placement is interesting. \\
\hline & Item 18 & I look forward to coming to this clinical placement. \\
\hline \multirow[t]{3}{*}{ Stimulus } & Item 19 & I put effort into what I do in the workplace. \\
\hline & Item 20 & I pay attention to what others are saying. \\
\hline & Item 21 & The pharmacy Preceptor talks with me as an individual. \\
\hline
\end{tabular}

* Indicates negative questions, where scores were reversed 
Surprisingly, students reported low satisfaction with their community placement experiences (Table 2). Less than half of the students enjoyed working at their community pharmacy placements, and about $46 \%$ of the students stated that they would like to return to their pharmacy placements. More than half of the students (55.9\%) reported that they put effort into their conduct in the work environment, and $62.3 \%$ of students focused on what was being said in the work environment. The mean score for motivation was $3.4 \pm 0.6$ (Table 2).

\section{DISCUSSION}

A relatively high score of students' opinions on engagement shows that students were well-occupied with their placements. Engagement in medical placement training settings is crucial to introduce qualified graduates in health care team. ${ }^{14}$ Engagement can be defined as the degree of attention, interest, involvement, and responsibility students take in their learning. The level of student engagement can affect student learning, development of self-improvement, and satisfaction. ${ }^{1,15}$

In this study, the mean score for engagement was 3.2 out of 5 , which implies that students did not appreciate the aims of the placements, assume responsibility for work environment assignments, or recognize learning opportunities. A similar study in Australia explored pharmacy students' opinion of experiential learning opportunities. The mean score was 4.2, indicating that these students were more engaged to their experiential community pharmacy placements than those in the present study. ${ }^{1}$ Our study did not investigate the factors that influenced the level of students' engagement with their placements. However, the low levels of engagement observed could be due to a variety of reasons related to preceptors or students or both.

Student satisfaction with their community placements has been documented as a critical component of patient care, and dissatisfaction can be related to not being involved in ward activities and insufficient support of medical staff. ${ }^{14}$ This study found that students' level of dissatisfaction towards their community placement experiences was neutral $(3.1 \pm 0.8)$. The level of student satisfaction with their community placement experiences was relatively low (3.3 \pm 0.9$)$. This value is lower than that reported by Fejzic et al., which was a mean score of 4.2 for student satisfaction with their community placement experiences. ${ }^{1}$ These results demonstrated that students had positive encounters, with students empowered by well-organized programs and preceptors. ${ }^{1}$ The low level of student satisfaction in the present study could be related to many reasons, including the backgrounds of the community pharmacists. It has been reported that most community pharmacists

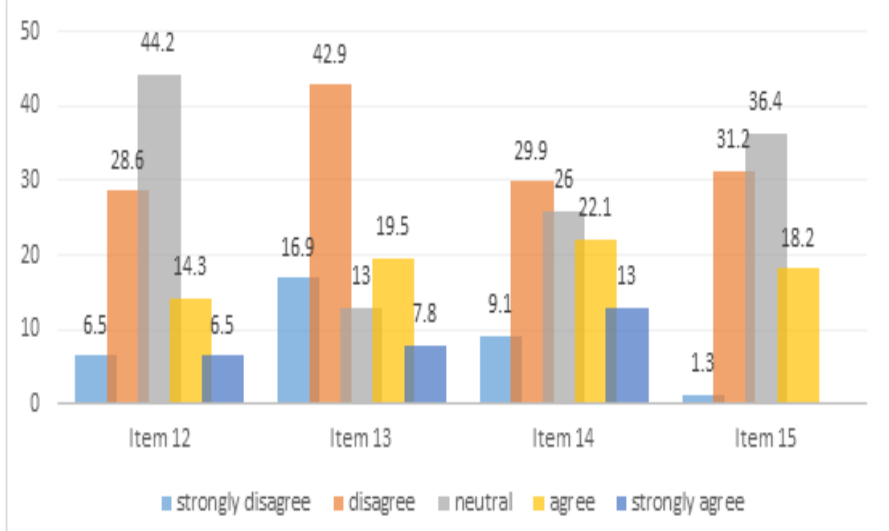

Figure 1: Opinions of students regarding Displeasure during community placement experiences.

Table 2: Opinions of pharmacy students regarding their placement experiences.

\begin{tabular}{|c|c|c|c|c|c|c|c|}
\hline \multirow[t]{2}{*}{ Subscales and Items } & & 1 & 2 & 3 & 4 & 5 & Mean (SD) \\
\hline & & N (\%) & N (\%) & N (\%) & N (\%) & N (\%) & Scores \\
\hline \multirow[t]{11}{*}{ Commitment } & Q1 & $6(7.8)$ & $14(18.2)$ & $21(27.3)$ & $31(40.3)$ & $5(6.5)$ & $3.2 \pm 0.5$ \\
\hline & Q2 & $6(7.8)$ & $8(10.4)$ & $28(36.4)$ & $31(40.3)$ & $4(5.2)$ & \\
\hline & Q3 & $4(5.2)$ & $7(9.1)$ & $20(26.0)$ & 35 (45.5) & $11(14.3)$ & \\
\hline & Q4 & $8(10.4)$ & $8(10.4)$ & $39(50.6)$ & $21(27.3)$ & $1(1.3)$ & \\
\hline & Q5 & $7(9.1)$ & $19(24.7)$ & $28(36.4)$ & $19(24.7)$ & $4(5.2)$ & \\
\hline & Q6 & $3(3.9)$ & $9(11.7)$ & $23(29.9)$ & $36(46.8)$ & $6(7.8)$ & \\
\hline & Q7 & $4(5.2)$ & $31(40.3)$ & $17(22.1)$ & $12(15.6)$ & $13(16.9)$ & \\
\hline & Q8 & $3(3.9)$ & $10(13.0)$ & $29(37.7)$ & $28(36.4)$ & $7(9.1)$ & \\
\hline & Q9 & $4(5.2)$ & $12(15.6)$ & $36(46.8)$ & $20(26.0)$ & $5(6.5)$ & \\
\hline & Q10 & $4(5.2)$ & $12(15.6)$ & $29(37.7)$ & $28(36.4)$ & $4(5.2)$ & \\
\hline & Q11 & $1(1.3)$ & $7(9.1)$ & $43(55.8)$ & $23(29.9)$ & $3(3.9)$ & \\
\hline \multirow[t]{4}{*}{ Displeasure } & Q12 & $5(6.5)$ & $22(28.6)$ & $34(44.2)$ & $11(14.3)$ & $5(6.5)$ & $3.1 \pm 0.8$ \\
\hline & Q13 & $13(16.9)$ & 33 (42.9) & $10(13.0)$ & 15 (19.5) & $6(7.8)$ & \\
\hline & Q14 & $7(9.1)$ & 23 (29.9) & $20(26.0)$ & $17(22.1)$ & $10(13.0)$ & \\
\hline & Q15 & $1(1.3)$ & $24(31.2)$ & $28(36.4)$ & $14(18.2)$ & $10(13.0)$ & \\
\hline \multirow[t]{3}{*}{ Fulfillment } & Q16 & $4(5.2)$ & $12(15.6)$ & $25(32.5)$ & $30(39.0)$ & $6(7.8)$ & $3.3 \pm 0.9$ \\
\hline & Q17 & $6(7.8)$ & $9(11.7)$ & $21(27.3)$ & $33(42.9)$ & $8(10.4)$ & \\
\hline & Q18 & $9(11.7)$ & $11(14.3)$ & $22(28.6)$ & $28(36.4)$ & $7(9.1)$ & \\
\hline \multirow[t]{3}{*}{ Stimulus } & Q19 & $2(2.6)$ & $8(10.4)$ & $24(31.2)$ & 33 (42.9) & $10(13.0)$ & $3.4 \pm 0.6$ \\
\hline & Q20 & $1(1.3)$ & $14(18.2)$ & $14(18.2)$ & $46(59.7)$ & $2(2.6)$ & \\
\hline & Q21 & $4(5.2)$ & $6(7.8)$ & $24(31.2)$ & 38 (49.4) & $5(6.5)$ & \\
\hline
\end{tabular}


do not provide pharmaceutical care in community pharmacy settings. ${ }^{16}$ Additionally, the placements may not be enjoyable, the experience may not improve their clinical skills, and students may not feel ready for clinical placements in the future. The preceptors' jobs are dynamic, requiring a commitment to recognizing the needs of the students and ensuring that they are equipped to be proficient, educated, and mindful in their practice. ${ }^{17}$ Students in this study reported negative experiences with their community pharmacy placements, stating that the placements did not motivate them. This leads to negative expectations and a lack of confidence.

\section{Recommendations}

This study considered the numerous positive and negative aspects of the clinical experiences of pharmacy students during their community pharmacy placements. It highlights the need for coordinated efforts between the advanced education and medical services segments to ensure that clinical learning conditions meet the necessities of undergraduate pharmacy students. This joint effort should develop imaginative models for clinical instruction that account for current wellbeing and training. Sustainable conditions can be created when the hierarchical points of the benefit and instructive divisions converge in an atmosphere that supports synergistic learning, trust, and common regard. ${ }^{17}$ Although the findings of this study are promising, there were some limitations. For instance, it was conducted in only one university for men in Saudi Arabia, so the outcomes may not completely reflect the opinions of all pharmacy students. In any case, these data cannot be ignored; however, the results should be considered and put into action while translating the outcomes. Furthermore, a larger study involving both male and female students is recommended to confirm the results of this study.

\section{CONCLUSION}

This study showed that the pharmacy students had relatively low engagement with their pharmacy placements experience. Also, pharmacy students had low levels of satisfaction during their community pharmacy experiential placements. Further studies are needed to evaluate the various factors influencing student satisfaction during community pharmacy placements.

\section{ACKNOWLEDGEMENT}

The author would like to thanks the Deanship of Scientific Research and Research Center at the College of Pharmacy, King Saud University, Saudi Arabia.

\section{CONFLICT OF INTEREST}

The author declares no conflict of interest.

\section{ABBREVIATIONS}

SPSS: Statistical Package for Social Science.

\section{REFERENCES}

1. Fejzic J, Henderson A, Smith NA, Mey A. Community pharmacy experiential placement: Comparison of preceptor and student perspectives in an Australian postgraduate pharmacy Programme. Pharmacy Educ. 2013;17;13.

2. Egan T, Jaye C. Communities of clinical practice: The social organization of clinical learning. Health: 2009;13(1):107-25.

3. Boyle CJ, Carr-Lopez S, Kawahara NE, Kieser MA, See CJ, Smith GB. Report of the preceptor development task force subcommittee two. Am J Pharm Educ. 2002;66(4; Supp):42S-3S.

4. Marriott J, Taylor S, Simpson M, Bull R, Galbraith K, Howarth H, et al. Australian national strategy for pharmacy preceptor education and support. Aust J Rural Health. 2005;13(2):83-90.

5. Al-Arifi MN. Community pharmacist perception and attitude toward ethical issues at community pharmacy setting in central Saudi Arabia. Saudi Pharm J. 2014;22(4):315-25

6. Almeman A, Al-jedai A. Pharmacy practice in the Kingdom of Saudi Arabia. In Pharmacy practice in developing countries. Academic Press. 2016;1:171-97.

7. Shamim S, Rasheed H. Continuing professional development for pharmacists in three countries with developing health systems. Curr Pharm Teach Learn $2021 ; 3$

8. Applebe GE, Wingfield J. Dale and Applebe's Pharmacy law and ethics. Pharmaceutical Press; 2005.

9. Dreischulte T, Fernandez-Llimos F. Current perceptions of the term Clinical Pharmacy and its relationship to Pharmaceutical Care: A survey of members of the European Society of Clinical Pharmacy. Int J Clin Pharm. 2016;38(6):144556.

10. Al-Jedai A, Qaisi S, Al-Meman A. Pharmacy practice and the health care system in Saudi Arabia. Can J Hosp Pharm. 2016;69(3):231.

11. Alhomoud FK, AlGhalawin L, AlGofari G, AIDjani W, Ameer A, Alhomoud F. Career choices and preferences of Saudi pharmacy undergraduates: A cross sectional study. Saudi Pharmaceutical Journal. 2019;27(4):467-74.

12. Rodger S, Webb G, Devitt L, Gilbert J, Wrightson P, McMeeken J. Clinical education and practice placements in the allied health professions: An international perspective. J Allied Health. 2008;37(1):53-62.

13. Balkhi B, Alghamdi A, Alhossan A, Alhamami A, Asiri YA. Pharmacy student's attitude and perception toward working in community pharmacy in Saudi Arabia. Saudi Pharm J. 2020;28(4):397-402.

14. Hopper MK, Kaiser AN. Engagement and higher order skill proficiency of students completing a medical physiology course in three diverse learning environments. Adv Physiol Educ. 2018;42(3):429-38.

15. Alanazi AS, Alfadl AA, Hussain AS. Pharmaceutical care in the community pharmacies of Saudi Arabia: Present status and possibilities for improvement. Saudi J Med Med Sci. 2016;4(1):9.

16. Abouelfettoh A, AlMumtin S. Nursing students' satisfaction with their clinical placement. J Sci Res Rep. 2015;490-500.

17. Ebu Enyan NI, Amoo SA, Boso CM, Doe PF, Slager D. A Multisite Study on Knowledge, Perceived Motivators, and Perceived Inhibitors to Precepting Nursing Students within the Clinical Environment in Ghana. Nurs Res Pract. 2021 Jan 18;2021:6686898. doi: 10.1155/2021/6686898.

Article History: Submission Date : 15-02-2021; Revised Date : 21-03-2021; Acceptance Date : 04-05-2021.

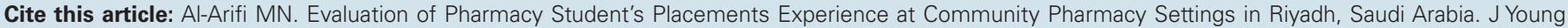
Pharm. 2021;13(2):143-6. 